\title{
Small bite, big threat
}

\author{
B H N Yasmeen ${ }^{1}$
}

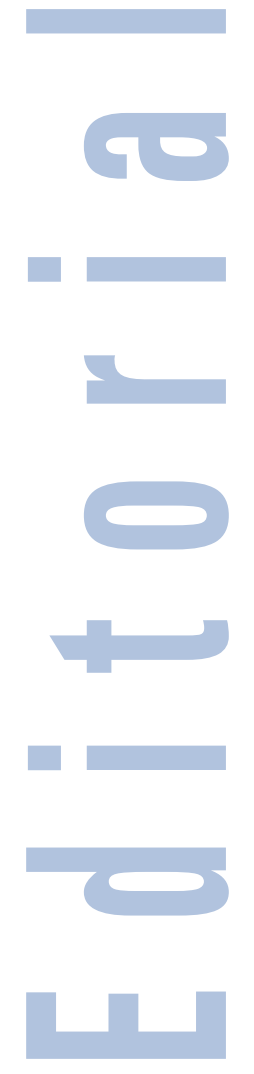

1 Dr. B H Nazma Yasmeen
MBBS, MCPS, MD (Paed)
Editor
Northern International
Medical College Journal

Associate Professor Dept. of Paediatrics Northern International Medical College, Dhaka email :

drnazmayasmeen @ yahoo.com
Every year 7 April World Health Organization (WHO) celebrates "World Health Day" to draw the attention of a public health problem of global concern and what needs to be done to address it. The date of 7 April marks the anniversary of the founding of WHO in 1948.

The theme for World Health Day 2014 is vectorborne diseases. This year WHO is highlighting the serious and increasing threat of vectorborne diseases, with the slogan "Small bite, big threat".

Vector is any agent (person, animal or microorganism) that carries and transmits an infectious pathogen in to another living organism. ${ }^{1}$

Every year, a million people are killed by diseases that are carried by vectors including mosquito, ticks, flies, sandflies, fleas, bugs. These vector-borne diseases includes malaria, dengue, yellow fever, schistosomiasis, leishmaniasis, chagas disease, yellow fever, lymphatic filariasis and onchocerciasis etc. WHO estimated that one sixth of the illness and disability suffered worldwide is due to vectorborne diseases, with more than half the world's population currently estimated to be at risk of these diseases.

The Aedes aegypti mosquito is capable of transmitting chikungunya, dengue and yellow fever virus. It bites most actively two hours before and after dawn and dusk. Now dengue fever, together with associated dengue haemorrhagic fever (DHF), is the world's fastest growing vector borne disease. It is now found in 100 countries, putting more than 2.5 billion people - over $40 \%$ of the world's population - at risk. Dengue has recently been reported in China, Portugal and the state of Florida, in the United States of America. ${ }^{2}$

The Anopheles mosquito can transmit malaria. Worldwide, malaria is a leading cause of premature mortality, particularly in children under the age of five, with around 2 million deaths annually, according to the Centers for Disease Control. In Africa, a child dies every 45 seconds with malaria. ${ }^{3}$ In countries where malaria is well established the WHO estimates countries lose $1.3 \%$ annual economic income due to the disease. ${ }^{4}$

Some species of mosquito can carry the $L$. donovani, which causes lymphatic filariasis and leishmaniasis and can develop swelling in the legs(elephantiasis) or serious deformities. Worldwide, around 40 million people are living with a filariasis disability. ${ }^{5}$

Chagas disease is caused by a blood-sucking "kissing bug" and can lead to problems in the heart and intestine. These statistics indicates Mosquitoes and ticks might have small bites, but their bites are a big threat for us.

This year WHO launched the campaign "Small bite, big threat" to educate, to aware people about vector-borne diseases. WHO issued reports indicating that vector-borne diseases affect poor people, especially people living in areas that do not have adequate levels of sanitation, drinking water and housing. 2 Poorly designed irrigation and water systems, inadequate housing, poor waste disposal and water storage, deforestation and loss of biodiversity, all may be contributing factors to the most common vector-borne diseases like malaria, dengue and leishmaniasis.

There is no vaccine for most of these vectorborne diseases, no specific treatment is available for some of them eg. West Nile Virus and Dengue fever etc. However, even with effective treatments the high cost remains a huge barrier to most of the developing world's population. Therefore vector control remains the important cost effective way to protect the general people. Integrated vector control can decrease the risk of disease transmission. This approach, used by national and local governments, includes implementing rational insecticide usage, surveillance and actions like improving access to safe water, regular waste collection services, basic sanitation, education, hygiene and adequate housing quality.

Vector control focuses on utilizing preventative methods to control or eliminate vectors. Common preventative measures are: 
Habitat Control : Removing or reducing areas where vectors can easily breed can help to limit their growth. For example, stagnant water removal, destruction of old tires and cans which serve as mosquito breeding environments and good management of used water can reduce areas of excessive vector incidence.

Reducing Contact : Limiting exposure to vectors can reduce infection risks significantly. For example, bed nets, window screens on homes, or protective clothing, proper insect repellants can help to reduce the likelihood contact with vectors. To be effective this requires education and promotion of methods amongst the population to raise the awareness of vector threats. Trials of using insecticide-treated bednets in some malaria-endemic African countries have shown very substantial reduction in child and infant mortality ${ }^{6}$

Chemical Control : Insecticides, lanvicides, rodenticides, lethal ovitraps and repellents can be used to control vectors. For example, larvicides can be used in mosquito breeding zones; insecticides can be applied to house walls or bed nets, and use of personal repellents can reduce incidence of insect bites and thus infection. The use of pesticides for vector control is promoted by the WHO and has proven to be highly effective. ${ }^{7}$

Biological Control : The use of natural vector predators, such as bacterial toxins or botanical compounds, can help to control vector populations. Using fish that eat mosquito larvae or reducing breeding rates by introducing sterilized male tsetse flies have been shown to control vector populations and reduce infection risks. ${ }^{8}$

Some of the natural mosquito repellents for personl useage areNeem oil : neem is a great mosquito-repellent. A study published in the Journal of the American Mosquito Control Association ${ }^{9}$ found that mixing neem oil with coconut oil in a 1:1 ratio is a highly effective way to keep mosquitoes at bay. Being a potent antibacterial, anti-fungal, antiviral and anti-protozoal agent, neem lends skin a particular smell that wards off mosquitoes.

Eucalyptus and lemon oil: Recommended by the CDC (Center for Disease Control) as an effective insect-repellent, the mixture of lemon oil and eucalyptus oil is extremely effective in repelling mosquitoes-naturally. The way lemon oil and eucalyptus oil works is due to its active component cineole, which has both antiseptic and insect-repellent properties when applied to the skin. The best part about this mixture is that it is natural and does not have any side effects of chemical mosquito repellents.

Mint : According to a study published in the Journal of Bioresource Technology ${ }^{10}$ found that mint oil and mint extract is as effective as any other insect repellent.

Camphor: camphor has been found to have the longest mosquito repellent activity when compared to other natural products. ${ }^{11}$
Tulsi: According to data published in the Parasitology Research J ournal ${ }^{12}$ tulsi was extremely effective in killing mosquito larvae and help to keep mosquitoes away. The plant has properties that do not allow mosquitoes to breed and will prevent them to enter in to the home .

Vector control in many third world areas can have tremendous impacts as it increases mortality rates, especially among infants. ${ }^{13}$

\section{References}

1. Last, James, A Dictionary of Epidemiology. New York: Oxford University Press. ed. 2001: 185. ISBN 978-0-19-514169-6. OCLC 207797812.

2. World Health Day 2014: Preventing vector-borne diseaseswww.who.int/ mediacentre/news/releases/2014/small-bite-big.../en

3. "Malaria Fact Sheet". World Health Organization. 2010.

4. J L Gallup, J D Sachs. The Economic Burden of Malaria, Center for International Development at Harvard, Oct 1998, http://www.earth.columbia.edu/ sitefiles/file/about/director/pubs/mal_wb.pdf

5. "Lymphatic filariasis". Health Topics A to Z. Source: The World Health Organization Retrieved 2013-03-24.

6. Sachs J, Malaney P. The economic and social burden of malaria. Nature, 2002, 415: 680-685

7. "Pesticides and their application for the control of vectors and pests of public health importance" (pdf). World Health Organization. 2006.

8. Vreysen, MJ ; et al. (2000). "Glossina austeni (Diptera: Glossinidae) eradicated on the island of Unguja, Zanzibar, using the sterile insect technique". Journal of Economic Entomology93 (1): 123-135. doi:10.1603/0022-0493-93.1.123.

9. Sharma VP, Ansari MA, Razdan RK . Mosquito repellent action of neem (Azadirachta indica) oil. Journal of the American Mosquito Control Association[1993, 9(3):359-360] . (PMID:8245950)

10. M.A Ansari, Padma Vasudevan' Mamta Tandon, R.K Razdan. Larvicidal and mosquito repellent action of peppermint (Mentha piperita) Bioresource Technology. February 2000; 71( 3), 267-271

11. O. ChokechaijaroenpornN. Bunyapraphatsara S. Kongchuensin. Mosquito repellent activities of ocimum volatile oils. Phytomedicine September 1994, 1( 2), 135-139

12. C. Kamaraj, A. Abdul Rahuman, A. Bagavan. Antifeedant and larvicidal effects of plant Spodoptera litura (F.)and Say extracts against, Aedes aegyptiCulex quinquefasciatus $\mathrm{L}$. Parasitology Research July 2008; 103(2) 325-331

13. "10 Facts on Malaria". World Health Organization. 2009. 